\title{
Data-Driven Definitions for Active and Structural MRI Lesions in the Sacroiliac Joint in Spondyloarthritis and their Predictive Utility
}

Walter P. Maksymowych ${ }^{1,2}$, Robert G. Lambert ${ }^{1}$, Xenofon Baraliakos ${ }^{3}$, Ulrich Weber ${ }^{4}$, Pedro M. Machado $^{5}$, Susanne J. Pedersen ${ }^{6}$, Manouk de Hooge ${ }^{7}$, Joachim Sieper ${ }^{8}$, Stephanie Wichuk ${ }^{1}$, Denis Poddubnyy ${ }^{8}$, Martin Rudwaleit ${ }^{9}$, Désirée van der Heijde ${ }^{10}$, Robert Landewe ${ }^{11}$, Iris Eshed ${ }^{12}$, Mikkel Ostergaard 6

\section{Author degrees and affiliations}

Walter P. Maksymowych: Department of Medicine, University of Alberta, Edmonton, Canada; CARE Arthritis, Edmonton, Canada

Robert G. Lambert: Department of Radiology and Diagnostic Imaging, University of Alberta, Edmonton, Canada and Medical Imaging Consultants, Edmonton, Canada.

Xenofon Baraliakos: Rheumazentrum Ruhrgebiet Herne, Ruhr-University Bochum, Germany Ulrich Weber: Ulrich Weber. MD. Danish Hospital for Rheumatic Diseases, University Hospital of Southern Denmark, Sønderborg, Denmark; Department of Regional Health Research, University of Southern Denmark, Odense, Denmark

Pedro M Machado: Department of Rheumatology, University College London Hospitals NHS Foundation Trust, London, UK; Department of Rheumatology, Northwick Park Hospital, London North West University Healthcare NHS Trust, London, UK; Centre for Rheumatology and MRC Centre for Neuromuscular Diseases, University College London, London, UK

Susanne J. Pedersen: Copenhagen Center for Arthritis Research, Center for Rheumatology and Spine Diseases, Rigshospitalet, Copenhagen, Denmark

(C) The Author(s) 2021. Published by Oxford University Press on behalf of the British Society for Rheumatology. All rights reserved. For permissions, please email: journals.permissions@oup.com 
Manouk de Hooge: VIB Inflammation Research Center, Ghent University, Ghent, Belgium and Rheumatology Department, Ghent University Hospital, Ghent, Belgium

Joachim Sieper: Charité - Universitätsmedizin Berlin and German Rheumatism Research

Centre, Berlin, Germany

Stephanie Wichuk: Research Associate, Department of Medicine, University of Alberta, Edmonton, Canada

Denis Poddubnyy: Charité - Universitätsmedizin Berlin and German Rheumatism Research Centre, Berlin, Germany

Martin Rudwaleit: Klinikum Bielefeld, Bielefeld, and Charité - Universitätsmedizin Berlin, Berlin, Germany

Désirée van der Heijde: Leiden University Medical Centre, Leiden, the Netherlands

Robert Landewe: Academic Medical Center, University of Amsterdam, Amsterdam, The

Netherlands, and Atrium Medical Center, Heerlen, the Netherlands

Iris Eshed: Sheba Medical Center, affiliated to the Sackler school of medicine, Tel-Aviv university, Tel Aviv, Israel

Mikkel Østergaard: Copenhagen Center for Arthritis Research, Center for Rheumatology and Spine Diseases, Rigshospitalet, Glostrup, and Department of Clinical Medicine, University of Copenhagen, Copenhagen, Denmark

Corresponding Author: Walter P. Maksymowych

568 Heritage Medical Research Building, University of Alberta, Edmonton, Alberta, T6R 2G8, Canada. Email: walter.maksymowych@ualberta.ca

Orcid Number: 0000-0002-1291-1755 


\section{ABSTRACT}

Objectives. To determine quantitative sacroiliac joint (SIJ) MRI lesion cut-offs that optimally define a positive MRI for inflammatory and structural lesions typical of axial spondyloarthritis $(\operatorname{axSpA})$ and that predict clinical diagnosis.

Methods. The ASAS MRI group assessed MRIs from the ASAS Classification Cohort in two reading exercises: A. 169 cases and 7 central readers; B. 107 cases and 8 central readers. We calculated sensitivity/specificity for the number of SIJ quadrants or slices with bone marrow edema (BME), erosion, fat lesion, where a majority of central readers had high confidence there was a definite active or structural lesion. Cut-offs with $\geq 95 \%$ specificity were analyzed for their predictive utility for follow-up rheumatologist diagnosis of axSpA by calculating positive/negative predictive values (PPV/NPV) and selecting cut-offs with PPV $\geq 95 \%$.

Results. Active or structural lesions typical of axSpA on MRI had PPV $\geq 95 \%$ for clinical diagnosis of axSpA. Cut-offs that best reflect definite active lesion typical of axSpA were either $\geq 4$ SIJ quadrants with BME at any location or at the same location in $\geq 3$ consecutive slices. For definite structural lesion, the optimal cut-offs were any one of $\geq 3$ SIJ quadrants with erosion or $\geq 5$ with fat lesion, erosion at the same location for $\geq 2$ consecutive slices, fat lesion at the same location for $\geq 3$ consecutive slices, or presence of a 'deep' $(>1 \mathrm{~cm})$ fat lesion.

Conclusion. We propose cut-offs for definite active and structural lesions typical of axSpA that have high PPV for a long-term clinical diagnosis of axSpA for application in disease classification and clinical research.

Key Words. Spondyloarthritis, magnetic resonance imaging, sacroiliac joint, definitions, predictive validity 


\section{Rheumatology key messages}

- $\quad \mathrm{BME}$ on MRI is considered highly suggestive of axSpA if present in $\geq 4$ SIJ quadrants or $\geq 3$ consecutive SIJ slices.

- A positive MRI for structural lesions in the SIJ comprises $\geq 3$ SIJ quadrants with erosion or $\geq 5$ SIJ quadrants with fat lesions.

- MRI cut-offs for definite active and structural lesions typical of axSpA have very high PPV for clinical diagnosis of axSpA.

\section{INTRODUCTION}

Magnetic resonance imaging (MRI) of the sacroiliac joints (SIJ) represents a major advance in the evaluation of axial spondyloarthritis (axSpA) because it permits detection of inflammatory and structural changes in the subchondral bone marrow that are not visible on conventional radiography of the SIJ [1]. These include bone marrow edema (BME), inflammation in an erosion cavity, and fat lesion [2]. In addition, it is far more sensitive than plain radiography for detection of erosions [3-6]. Consequently, MRI features of sacroiliitis have been incorporated into the ASAS classification criteria where patients diagnosed with axSpA can be classified as having axSpA according to an imaging arm. This requires the presence of either MRI or radiographic criteria for sacroiliitis and at least one clinical feature of axSpA [7].

A positive MRI indicative of sacroiliitis was first defined in 2009 according to a consensus opinion of ASAS experts in MRI as the presence of subchondral bone marrow edema (BME) that is "highly suggestive" of axSpA on STIR/fat-suppressed T2 (T2FS) or osteitis on contrastenhanced fat-suppressed T1 (T1FS+Gd) MRI [8]. This ASAS definition included a quantitative 
component, this being the presence of two BME lesions on a single semicoronal slice through the SIJ or a single lesion on two consecutive semicoronal slices. In a subsequent 2016 reappraisal of this ASAS definition by consensus opinion of ASAS experts it was agreed that subchondral BME "highly suggestive" of axSpA was the defining characteristic although a quantitative component was not stipulated [9]. However, what constitutes a lesion that is "highly suggestive of axSpA" may vary considerably even among expert readers. Some reports have applied the Spondyloarthritis Research Consortium of Canada (SPARCC) MRI SIJ inflammation scoring method, which records the presence/absence of BME in SIJ quadrants on consecutive semicoronal slices [10]. A SPARCC cut-off score of $\geq 2$ SIJ quadrants with BME was reported to best reflect central reader consensus as to the presence of BME meeting the ASAS definition [11]. Several cross-sectional studies have since reported that false positive BME lesions meeting the ASAS definition may be observed in $20-40 \%$ of healthy individuals as well as those with non-specific back disorders $[6,12-15]$. This is a potential concern because definitions intended for classification purposes may be misused for diagnosis.

Recent advances in our understanding of MRI lesions in the SIJ prompted the ASAS-MRI Working Group (WG) to conduct a reappraisal and validation of new and revised ASAS MRI lesion definitions in a multi-reader exercise of MRI scans from patients with undiagnosed back pain who were recruited to the ASAS classification cohort (ASAS-CC) [7]. Data from this cohort led to the development of the ASAS classification criteria and follow up of the ASAS-CC after 4.4 years indicated high positive predictive value of the criteria for rheumatologist diagnosis of axSpA [16]. We employed a novel study design that first determined lesion cut-offs that optimally define an active or structural MRI lesion considered typical of axSpA as determined by 
the majority of central readers from the ASAS-WG. We then assessed the predictive utility of these lesion cut-offs for rheumatologist's diagnosis of $\operatorname{axSpA}$ at the follow up assessment of the ASAS-CC.

\section{METHODS}

The study cohort, local rheumatologist assessments, imaging assessments, and follow up of the ASAS-CC have been reported previously $[2,7,16]$. The ASAS-CC is an inception cohort of patients with undiagnosed back pain of $\geq 3$ months duration and with onset $<45$ years referred to a rheumatologist with suspicion of axSpA. Central reader MRI evaluations were conducted after diagnosis had been ascertained by local rheumatologists both at baseline and after 4.4 years of follow up of this cohort.

ASAS eCRF for evaluation of MRI lesions in the SIJ. The online-available eCRF comprised two sections:

A. Data was first entered into a global scoring page where central readers recorded the presence/absence of each type of active and structural lesion in iliac and sacral portions of each SIJ and whether the scan met the ASAS definition for a positive MRI $(8,9)$. Central readers also provided a yes/no response and degree of confidence rating ( -4 (definitely absent) to +4 (definitely present) to two questions from the original ASAS-CC eCRF (7):

Q1. "Are there typical acute/active inflammatory lesions compatible with axial SpA present in SI joints or at entheseal sites outside the SI joint?" Q2. "Are typical chronic inflammatory lesions present in or around SI joints?"

B. After global assessment, data was entered into a granular scoring web-based interface where inflammatory and structural lesions were recorded on consecutive semicoronal 
slices [17]. All slices with a minimum $1 \mathrm{~cm}$ vertical height of visible SIJ were scored and SIJ quadrants were defined according to established rules [18]. BME was recorded in SIJ quadrants and structural lesions were recorded in either SIJ quadrants (erosion, fat lesion, sclerosis) or upper and lower SIJ halves (fat metaplasia in an erosion cavity (FM-EC), ankylosis) as previously defined [19].

Reading exercises. Two central reader exercises were conducted. Validated calibration modules aimed at standardization of the reading methodology were provided online for review prior to the readings [20,21]. In the first (exercise A), 7 central readers from the ASAS-MRI WG assessed all available baseline MRI scans. In the second exercise (exercise B) which was conducted 14 months after exercise A, the same 7 readers plus one additional reader from the ASAS-MRI WG assessed pairs of baseline and follow up MRI scans blinded to time point from cases who had MRI performed at baseline and follow up (average 4.4 years post-baseline). The eCRF for this exercise included an additional question on the global scoring page that asked the reader to respond to the following question: Q3, Is the MRI scan indicative of the presence of axSpA (yes/no).

Statistics. In order to generate optimal cut-offs that reflect active or structural lesions typical of axSpA, we first calculated sensitivity and specificity for the number of SIJ quadrants with BME, erosion, fat lesion, and sclerosis where central readers considered there was a definite active or structural lesion present on the MRI scan. A definite lesion was deemed present where a majority of central readers agreed as to the presence of an active or structural lesion typical of axSpA with high confidence $(\geq+3$ on the -4 to +4 rating scale) in their responses to Q1 and Q2, which 
constituted the external standards. An additional external standard was the definite presence of an ASAS positive MRI (BME "highly suggestive" of axSpA as per the 2016 definition). We similarly analyzed optimal cut-offs for the number of consecutive MRI slices that had active or structural lesions. We pre-specified optimal cut-offs as requiring specificity of $\geq 95 \%$ for a definite lesion.

We then assessed the predictive utility of baseline MRI data by calculating the sensitivity, specificity, positive and negative predictive values (PPV, NPV) for rheumatologist diagnosis of axSpA at follow up (average of 4.4 years) of the following global MRI variables: MRI indicative of $\operatorname{axSpA}(\mathrm{yes} / \mathrm{no})$, active lesions typical of $\operatorname{axSpA}(\mathrm{yes} / \mathrm{no})(\mathrm{Q} 1)$, structural lesions typical of $\operatorname{axSpA}(\mathrm{yes} / \mathrm{no})(\mathrm{Q} 2)$. We then tested the predictive utility of the optimal SIJ quadrants/slice cutoffs identified in the prior analysis as having specificity of $\geq 95 \%$ for a definite lesion. Both specificity of $\geq 95 \%$ for a definite lesion as well as a PPV of $\geq 95 \%$ were considered requirements for designation of cut-offs for defining a positive MRI for active or structural lesions.

\section{RESULTS}

\section{Patient characteristics and frequencies of MRI lesions}

For exercise A, scans with DICOM sequences and rheumatologist diagnosis at baseline were available from 169 cases and for 91 cases that also had a rheumatologist diagnosis at follow up (Table 1). Cases diagnosed with axSpA at baseline $(114(67.4 \%))$ had significantly more clinical SpA features (3.4 vs 1.6), higher frequency of B27 positive (52.6\% vs $21.8 \%$ ), elevated CRP (37.7\% vs $14.5 \%)$, and definite radiographic sacroiliitis according to modified New York criteria 
(28.8\% vs $1.9 \%)$. Similar differences in these patient characteristics according to diagnosis of axSpA were also present at follow up. Active lesions typical of axSpA were observed on baseline MRI by a majority of readers $(\geq 4 / 7)$ in $35.8 \%$ and $33.3 \%$ of cases diagnosed with axSpA at baseline and follow up, respectively, as compared to only $2.0 \%$ and $5.9 \%$ diagnosed as nonaxSpA. Structural lesions typical of axSpA were observed on baseline MRI scans by a majority of readers $(\geq 4 / 7)$ in $32.4 \%$ and $36.5 \%$ of cases diagnosed with axSpA at baseline and follow up, respectively, as compared to $6.8 \%$ and $0 \%$ diagnosed as non-axSpA (Table 1). Patient characteristics and frequencies of active and structural MRI lesions typical of axSpA in the 107 cases assessed in exercise B were similar to those in exercise A and have been reported previously [22].

\section{Number of SIJ Quadrants that Reflect Definite Active or Structural Lesions Typical of}

\section{$\operatorname{AxSpA}$}

The cut-off for number of SIJ quadrants with BME at any location that reflected majority central reader designation of a definite active lesion typical of axSpA or an ASAS positive MRI (BME that is "highly suggestive" of axSpA) according to the pre-defined specificity of $\geq 95 \%$ was $\geq 4$ (Table 2). The presence of BME at the same location (i.e. same SIJ quadrant) in $\geq 3$ consecutive slices also attained specificity of $\geq 95 \%$ for a definite active lesion or an ASAS positive MRI by the majority of central readers (Table 3).

The cut-offs for number of SIJ quadrants that best reflected a definite structural lesion typical of axSpA according to the pre-defined specificity of $\geq 95 \%$ was $\geq 3$ for erosion, $\geq 5$ for fat lesion, and $\geq 7$ for sclerosis (Table 2). A single SIJ quadrant or slice with an ASAS-defined fat lesion $>1 \mathrm{~cm}$ 
in depth had a specificity of $\geq 95 \%$ for a definite structural lesion and specificity of $97.5 \%$ when present at the same location in $\geq 2$ consecutive slices (Tables 2 and 3 ). The presence of erosion at the same location in $\geq 2$ consecutive slices had $\geq 95 \%$ specificity while a fat lesion required $\geq 3$ consecutive slices. The combination of fat lesion $>1 \mathrm{~cm}$ in depth in $\geq 1$ SIJ quadrant and erosion in $\geq 1$ SIJ quadrant (not necessarily the same quadrant) increased specificity to $99.2 \%$. Additional combinations of fat lesion and erosion cut-offs did not enhance specificity.

\section{Predictive Utility of Baseline MRI for Axial Spondyloarthritis}

Analysis of baseline MRI scans in exercise A demonstrated that both active and structural lesions typical of axSpA, as well as designation of an ASAS positive MRI, detected by a majority of readers $(\geq 4 / 7)$ had very high PPV ( $\geq 95 \%$ ) for a follow up diagnosis of axSpA (Table 4). PPV for an 'ASAS positive MRI' was very similar to the PPV of 'active lesions typical of axSpA (Q1)' even though the former assesses only BME while the latter includes all active lesions in the SIJ. However, NPV was low $(<50 \%)$ irrespective of the type of lesion recorded by central readers. In exercise $\mathrm{B}$, baseline MRI that was considered indicative of axSpA (Q3) by a majority of readers $(\geq 5 / 8)$ had $100 \%$ predictive utility for follow up diagnosis of axSpA. Both active and structural lesions had comparably high PPV. NPV was low $(<50 \%)$ irrespective of the type of lesion and also for overall MRI global evaluation.

\section{Predictive Validity of Individual SIJ Lesion Cut-offs for Rheumatologist Diagnosis of}

\section{AxSpA}

The presence of BME in $\geq 4$ SIJ quadrants or at the same location in $\geq 3$ SIJ slices on baseline MRI had very high PPV ( $\geq 95 \%$ ) for follow up diagnosis of axSpA assessed by the 
rheumatologist (Table 5). This was comparable to the performance of the baseline global MRI assessment for 'active lesions typical of axSpA' and 'ASAS positive MRI' (Table 4), though with a slightly lower NPV.

The presence of erosion in $\geq 3$ SIJ quadrants or at the same location in $\geq 2$ SIJ slices on baseline MRI had very high PPV ( $\geq 95 \%$ ) for diagnosis of axSpA (Table 5). The presence of fat lesion in $\geq 5$ SIJ quadrants, or at the same location in $\geq 3$ SIJ slices, or with depth $>1 \mathrm{~cm}$ in $\geq 2$ SIJ quadrants also had PPV $\geq 95 \%$. The performance of these structural lesion cut-offs was very comparable to the performance of the baseline global MRI assessment for 'structural lesions typical of axSpA', though with a slightly lower NPV. Examples of a positive MRI for active or structural lesions in the SIJ are provided in Figure 1.

\section{Predictive Validity of Combinations of SIJ Lesion Cut-offs for Rheumatologist Diagnosis of}

\section{$\operatorname{AxSpA}$}

Overall, combining cut-offs for different SIJ lesions did not substantially enhance predictive utility when compared to the cut-offs for individual lesions (Supplementary Table S1, available at Rheumatology online). For active lesions, there was slight improvement in predictive utility when cut-offs for fat lesion were combined with cut-offs for BME, primarily because of enhanced sensitivity without substantial compromise of specificity. For structural lesions, there was also slight improvement in predictive utility when cut-offs for fat lesion were combined with cut-offs for erosion due to enhanced sensitivity. 


\section{DISCUSSION}

We report several observations that are highly relevant to the interpretation of MRI scans for both diagnosis and classification of axSpA. First, both active and structural MRI lesions considered typical of axSpA had equally high predictive utility for rheumatologist's follow up diagnosis of axSpA in patients with undiagnosed back pain referred with suspicion of axSpA. Second, ASASdefined BME in $\geq 4$ SIJ quadrants at any location or in the same location on $\geq 3$ consecutive slices were optimal for defining a definite active lesion typical of axSpA. Third, ASAS-defined erosion in $\geq 3$ SIJ quadrants or at the same location in $\geq 2$ consecutive slices and ASAS-defined fat lesion in $\geq 5$ SIJ quadrants or $\geq 3$ consecutive slices provided similarly high specificities and PPVs for defining a definite structural lesion typical of axSpA. Finally, we demonstrated that all these MRI lesion cut-offs had very high ( $\geq 95 \%)$ PPV for rheumatologist's follow up diagnosis of axSpA that was comparable to the predictive utility of global MRI evaluation.

Our data-driven definitions for an active lesion typical of axSpA would be consistent with recent studies describing false positive BME in up to $40 \%$ of individuals without axSpA when the cutoff applied was BME in only $\geq 2$ SIJ quadrants or in $\geq 2$ consecutive slices [12-15]. One previous study that assessed patients diagnosed by a rheumatologist with axSpA and those with nonspecific back pain or healthy controls demonstrated that BME in $\geq 3$ and $\geq 4$ SIJ quadrants had much higher specificity for axSpA (89\% and 92\%, respectively) without substantial decrease in sensitivity (75\% and $70 \%$, respectively) compared to a cut-off of $\geq 2$ SIJ quadrants (sensitivity $80 \%$, specificity $76 \%$ ) [15]. However, this latter study was only cross-sectional and therefore did not analyze predictive utility of MRI lesion cut-offs for rheumatologist diagnosis of axSpA. A more recent Danish study reported that no controls had a BME score of $\geq 4$ SIJ quadrants except 
for women who had recently delivered a child [23]. An MRI study of patients with DISH also demonstrated that while $15.8 \%$ of patients met the ASAS definition of a positive MRI there were no DISH patients with BME in $\geq 4$ SIJ quadrants [24]. Moreover, a 2015 study demonstrated that a cutoff value of $\geq 2$ SIJ quadrants with BME optimally reflects the 3-reader consensus judgment of a positive versus negative MRI according to the ASAS definition [11]. These findings are not surprising because the quantitative part of the ASAS definition requires two BME lesions on a single slice or one lesion in 2 consecutive slices and most likely reflects circular reasoning. However, in our analysis of the ASAS-CC by central readers, designation of an ASAS positive MRI had much greater specificity of $97.4 \%$ for rheumatologist diagnosis of axSpA [22]. Moreover, a cut-off of $\geq 4$ SIJ quadrants with BME or BME at the same location in $\geq 3$ consecutive slices was optimal for reflecting an ASAS positive MRI considered "highly suggestive" of axSpA. This change over time in expert opinion as to what constitutes BME "highly suggestive" of axSpA is not surprising as data has accumulated demonstrating that false positive BME in the SIJ is a frequent observation in patients without axSpA. The thresholds for BME reported in this manuscript should not be applied to women within 6 months of delivery as several reports have highlighted a high frequency of substantial BME in the early post-partum period $[23,25,26]$.

There has been more limited analysis of MRI lesion cut-offs that might define a structural lesion typical of axSpA and such studies have been cross-sectional. One study that analyzed rheumatologist diagnosis of axSpA as external reference concluded that erosion in $\geq 2$ SIJ quadrants was optimal with specificity being 97\% [15]. A study from the SPACE cohort used the ASAS classification of axSpA as external reference for defining the presence of axSpA and 
concluded that $\geq 3$ erosion lesions or $\geq 3$ fat lesions or $\geq 5$ of these lesions in any combination, each individual lesion being defined as being present on $\geq 2$ consecutive slices, was optimal [27]. However, cut-offs according to number of SIJ quadrants with these lesions were not reported and it is therefore unclear how size of lesion was incorporated into these cut-offs. Moreover, in both studies, the lesion definition for erosion differed from the recently published ASAS-definition of erosion [2] which explicitly requires not only loss of the dark signal from cortical bone, which was included in previous studies, but also loss of the bright signal from adjacent marrow matrix. An erosion cut-off of $\geq 3$ SIJ quadrants derived from our analysis was more recently shown to differentiate between axSpA and controls, including post-partum women, in a Danish cohort with $\geq 95 \%$ specificity [23]. This was similarly reported as optimal for differentiation of patients with axSpA from those with DISH [24].

Opinion regarding the utility of fat lesions has evolved as it has become clear that it reflects the resolution of inflammation and has morphological characteristics on MRI that distinguish it from physiological fat infiltration. These have been incorporated in the recent update to the ASAS definitions of MRI lesions in the SIJ [2]. The revised ASAS definition for fat lesion includes distinct border, homogenous increase in T1W fat signal, and proximity to subchondral bone. The validation of this revised ASAS definition also included assessment of a 'deep' fat lesion, defined as having horizontal depth of $>1 \mathrm{~cm}$ from subchondral bone, because ASAS readers considered this might increase its specificity for axSpA. This was confirmed in this analysis and our data also demonstrated that a single 'deep' fat lesion on a single slice was $100 \%$ specific for axSpA. However, we caution against the use of a cut-off of " 1 " for any imaging-based observation of a 
single lesion on a single image as such a low threshold is more likely to be subject to reader misinterpretation or simulation by imaging artifact.

There are several study limitations. The high PPV values for MRI overall and MRI lesion cutoffs in diagnosis of axSpA reinforces the importance that rheumatologists assign to this imaging modality in ascertaining the diagnosis and some degree of circular reasoning could therefore account for the high PPV values. However, the primary aim of the analysis was to determine what MRI cut-offs best define active or structural MRI lesions typical of axSpA and not what cut-offs define a diagnosis of axSpA since diagnosis is a complex process that integrates clinical and imaging data. PPV values for specific MRI cut-offs did not always increase with a stricter definition because of the frequent co-occurrence of active and structural lesions in cases from this cohort, as reported previously [22]. Higher MRI lesion cut-offs for specific lesions did not necessarily eliminate cases that were negative for a diagnosis of axSpA because such patients had other MRI lesions that contributed to diagnostic ascertainment. The low NPV values indicate that the lack of MRI findings does not rule out $\operatorname{axSpA}$ and that rheumatologists do not rely only on MRI to make a diagnosis of axSpA. These cut-offs will require further validation in different practice settings where the prevalence of axSpA, which influences PPV, may differ from that observed in the ASAS-CC. The follow up of the ASAS-CC incurred substantial patient drop-out and a higher proportion of patients assessed at follow up had MRI inflammation than those lost to follow up [16]. This channeling bias may inflate PPV values for MRI parameters.

In conclusion, we employed a novel two-step study design and three external standards to identify optimal MRI SIJ lesion cut-offs that reflect definite active or structural MRI lesions 
typical of axSpA or an ASAS positive MRI "highly suggestive" for axSpA. The presence of BME in $\geq 4$ SIJ quadrants or in $\geq 3$ consecutive slices was optimal for both a definite active lesion and an ASAS positive MRI. The presence of erosion in $\geq 3$ SIJ quadrants or $\geq 2$ consecutive slices or the presence of fat lesion in $\geq 5$ SIJ quadrants or $\geq 3$ consecutive slices was optimal for a definite structural lesion typical of axSpA. The contribution of these cut-offs to the performance of classification criteria and diagnosis of axSpA will require testing in further studies. However, it is our hope that this work will finally lay to rest the frequent misuse of the quantitative component of the ASAS definition of a positive MRI, comprising BME in $\geq 2$ locations on one slice or in one location on $\geq 2$ consecutive slices, as a diagnostic criterion for axSpA.

\section{References}

1. Maksymowych WP. The role of imaging in the diagnosis and management of axial spondyloarthritis. Nat Rev Rheumatol 2019; 15: 657-72.

2. Maksymowych WP, Lambert RG, Ostergaard M, Pedersen SJ, Machado PM, Weber U, et al. MRI lesions in the sacroiliac joints of patients with spondyloarthritis: an update of definitions and validation by the ASAS MRI working group. Ann Rheum Dis 2019; 78:1550-8.

3. Diekhoff T, Hermann KGA, Greese J, Schwenke C, Poddubnyy D, Hamm B, et al. Comparison of MRI with radiography for detecting structural lesions of the sacroiliac joint using CT as standard of reference: results from the SIMACT study. Ann Rheum Dis 2017; 76: 1502-8. 
4. Dougados M, Sepriano A, Molto A, van Lunteren M, Ramiro S, de Hooge M, et al. Sacroiliac radiographic progression in recent onset axial spondyloarthritis: the 5-year data of the DESIR cohort. Ann Rheum Dis 2017; 76: 1823-8.

5. Ez-Zaitouni Z, Bakker PAC, van Lunteren M, Berg IJ, Landewe' R, van Osterhoutet M, et al. Presence of multiple spondyloarthritis (SpA) features is important but not sufficient for a diagnosis of axial spondyloarthritis: data from the SPondyloArthritis Caught Early (SPACE) cohort. Ann Rheum Dis 2017; 76: 1086-92.

6. Weber U, Lambert RG, Ostergaard M, Hodler J, Pedersen SJ, Maksymowych WP. The diagnostic utility of magnetic resonance imaging in spondylarthritis: an international multicenter evaluation of one hundred eighty-seven subjects. Arthritis Rheum 2010; 62: $3048-58$.

7. Rudwaleit M, van der Heijde D, Landewe' R, Listing J, Akkoc N, Brandt J, et al. The development of Assessment of SpondyloArthritis international Society (ASAS) classification criteria for axial spondyloarthritis (Part II): validation and final selection Ann Rheum Dis 2009; 68: 777-83.

8. Rudwaleit M, Jurik AG, Hermann KG, Landewe' R, van der Heijde D, Baraliakos X, et al. Defining active sacroiliitis on magnetic resonance imaging (MRI) for classification of axial spondyloarthritis: a consensual approach by the ASAS/OMERACT MRI group. Ann Rheum Dis 2009; 68: 1520-7.

9. Lambert RGW, Bakker PAC, van der Heijde D, Weber U, Rudwaleit M, Hermann KG, et al. Defining active sacroiliitis on MRI for classification of axial spondyloarthritis: update by the ASAS MRI working group. Ann Rheum Dis 2016; 75: 1958-63. 
10. Maksymowych WP, Inman RD, Salonen D, Dhillon SS, Williams M, Stone M, et al. Spondyloarthritis Research Consortium of Canada magnetic resonance imaging index for assessment of sacroiliac joint inflammation in ankylosing spondylitis. Arthritis Rheum 2005; 53: 703-9.

11. Van den Berg R, de Hooge M, Bakker PAC, van Gaalen F, Navarro-Compan V, Fagerli $\mathrm{KM}$, et al. Metric properties of the SPARCC score of the sacroiliac joints - data from baseline, 3-month, and 12-month followup in the SPACE Cohort. J Rheumatol 2015; 42; 1186-93.

12. De Winter J, de Hooge M, van de Sande M, de Jong H, van Hoeven L, de Konig A, Berg IJ, et al. Magnetic resonance imaging of the sacroiliac joints indicating sacroiliitis according to the Assessment of SpondyloArthritis international Society definition in healthy individuals, runners, and women with postpartum back pain. Arthritis Rheumatol 2018; 70: 1042-8.

13. Weber U, Jurik AG, Zejden A, Larsen E, Jorgensen SH, Rufibach K, et al. Frequency and anatomic distribution of magnetic resonance imaging features in the sacroiliac joints of young athletes: exploring "background noise" toward a data-driven definition of sacroiliitis in early spondyloarthritis. Arthritis Rheumatol 2018; 70: 736-45.

14. Varkas G, de Hooge M, Renson T, De Mits S, Carron P, Jacques P, et al. Effect of mechanical stress on magnetic resonance imaging of the sacroiliac joints: assessment of military recruits by magnetic resonance imaging study. Rheumatol 2018; 57: 508-13.

15. Weber U, Ostergaard M, Lambert RG, Pedersen SJ, Chan SM, Zubler V, et al. Candidate lesion-based criteria for defining a positive sacroiliac joint MRI in two cohorts of patients with axial spondyloarthritis. Ann Rheum Dis 2015; 74: 1976-82. 
16. Sepriano A, Landewe R, van der Heijde D, Sieper J, Akkoc N, Brandt J, et al. Predictive validity of the ASAS classification criteria for axial and peripheral spondyloarthritis after follow-up in the ASAS cohort: a final analysis. Ann Rheum Dis 2016; 75: 1034-42.

17. https://www.carearthritis.com/mriportal/mrimagine/index/

18. Maksymowych WP, Dhillon SS, Chiowchanwisawakit P, Pedersen SJ, Martinez B, Østergaard M, et al. Development and validation of web-based training modules for systematic evaluation of active inflammatory lesions in the spine and sacroiliac joints in spondyloarthritis. J Rheumatol 2009; 36: 48-57.

19. Maksymowych WP, Wichuk S, Chiowchanwisawakit P, Lambert RG, Pedersen SJ. Development and preliminary validation of the spondyloarthritis research Consortium of Canada magnetic resonance imaging Sacroiliac joint structural score. J Rheumatol 2015; 42: 79-86.

20. Maksymowych M, Boutrup H, Cheah J, Guglielmi R, Heffernan E, Jaremko J, et al. Validation of online calibration modules for the spondyloarthritis research Consortium of Canada MRI scores based on real-time experiential learning. Arthritis Rheumatol 2017; 69(suppl 10): 586

21. CARE Arthritis MRI scoring modules. Available: www.carearthritis.com/service/mriscoring-modules/

22. Maksymowych WP, Pedersen SJ, Weber U, Baraliakos X, Machado P, Eshed I, et al. Central reader evaluation of MRI scans of the sacroiliac joints from the ASAS classification cohort: Discrepancies with local readers and impact on the performance of the ASAS criteria. Ann Rheum Dis 2020; 79: 935-42 
23. Seven S, Østergaard M, Morsel-Carlsen L, Sorensen IG, Bonde B, Thamsborg G, et al. Magnetic resonance imaging of lesions in the sacroiliac joints for differentiation of patients with axial spondyloarthritis from control subjects with or without pelvic or buttock pain: a prospective, cross-sectional study of 204 participants. Arthritis Rheumatol 2019; 71: 2034-46.

24. Latourte A, Charlon S, Etcheto A, Feydy A, Allanore Y, Dougados M, et al. Imaging findings suggestive of axial spondyloarthritis in diffuse idiopathic skeletal hyperostosis. Arthritis Care Res 2018; 70:145-52.

25. Renson T, Depicker A, De Craemer AS, Deroo L, Varkas G, de Hooge M, et al. High prevalence of spondyloarthritis-like MRI lesions in postpartum women: a prospective analysis in relation to maternal, child and birth characteristics. Ann Rheum Dis 2020; 79: 929-34.

26. Hoballah A, Lukas C, Leplat C, Taourel P, Pialat JB, Sans N, et al. MRI of sacroiliac joints for the diagnosis of axial SpA: prevalence of inflammatory and structural lesions in nulliparous, early postpartum and late postpartum women. Ann Rheum Dis 2020; 79: 1063-9.

27. de Hooge M, van den Berg R, Navarro-Compan V, Reijnierse M, van Gaalen F, Fagerli K, et al. Patients with chronic back pain of short duration from the SPACE cohort: which MRI structural lesions in the sacroiliac joints and inflammatory and structural lesions in the spine are most specific for axial spondyloarthritis? Ann Rheum Dis 2016; 75: 130814. 


\section{Acknowledgements}

We thank Joel Paschke of CARE Arthritis for development of the web-based ASAS MRI eCRF and scoring interface, for processing of MR images for reading online, and for image data cleaning and processing. We thank Matthew Maksymowych and Mikhail Protopopov for processing of MR images for reading online.

PMM is supported by the National Institute for Health Research (NIHR) University College London Hospitals (UCLH) Biomedical Research Centre (BRC). The views expressed are those of the authors and not necessarily those of the National Institutes of Health (NIH), (UK) National Health Service (NHS), the NIHR, or the (UK) Department of Health.

Data sharing statement: The MRI scans and data from the readings reported in this study can be made available after submission of a study proposal to the ASAS MRI-WG. The raw data from this study has been deposited with the Assessments in SpondyloArthritis international Society.

Financial support/Grants: The study was supported by an unrestricted grant from the Assessments in SpondyloArthritis International Society (ASAS).

Disclosures: The authors have declared no conflicts of interest. 
Table 1. Baseline characteristics and SIJ MRI lesion frequencies by diagnosis of axSpA at baseline and followup.

\begin{tabular}{|c|c|c|c|c|c|c|c|c|c|c|}
\hline \multirow{4}{*}{ Baseline variables } & \multicolumn{10}{|c|}{ Local Rheumatologist Diagnosis } \\
\hline & \multicolumn{5}{|c|}{$\begin{array}{l}\text { Baseline Assessment } \\
\qquad(\mathrm{n}=169 *)\end{array}$} & \multicolumn{5}{|c|}{$\begin{array}{l}\text { Follow Up Assessment } \\
\qquad(\mathrm{n}=91 * *)\end{array}$} \\
\hline & \multicolumn{2}{|c|}{ Axial SpA=Yes } & \multicolumn{2}{|c|}{ Axial $\mathbf{S p A}=\mathbf{N o}$} & & \multicolumn{2}{|c|}{ Axial SpA=Yes } & \multicolumn{2}{|c|}{ Axial $\operatorname{SpA}=\mathbf{N o}$} & \multirow{2}{*}{ P value } \\
\hline & $\mathbf{n}$ & & $\mathbf{n}$ & & P value & $\mathbf{n}$ & & $\mathbf{n}$ & & \\
\hline Mean age (SD) & 114 & $34.5(8.1)$ & 55 & $33.6(10.1)$ & 0.58 & 71 & $35.4(7.9)$ & 20 & $35.9(7.6)$ & 0.81 \\
\hline Mean symptom duration (SD) & 97 & $6.8(6.7)$ & 51 & $6.8(8.0)$ & 0.98 & 60 & $7.8(7.1)$ & 19 & $8.8(7.9)$ & 0.64 \\
\hline Males, $\mathbf{N}(\%)$ & 114 & $54(47.4 \%)$ & 55 & $20(36.4 \%)$ & 0.18 & 71 & $36(50.7 \%)$ & 20 & $5(25 \%)$ & 0.042 \\
\hline Mean No. of SpA features (SD) & 114 & $3.4(1.5)$ & 55 & $1.6(1.5)$ & $<0.001$ & 71 & $3.6(1.5)$ & 20 & $1.5(1.1)$ & $<0.001$ \\
\hline B27 positive, $\mathbf{N}(\%)$ & 114 & $60(52.6 \%)$ & 55 & $12(21.8 \%)$ & $<0.001$ & 71 & $43(60.6 \%)$ & 20 & $3(15 \%)$ & $<0.001$ \\
\hline Elevated CRP, N(\%) & 114 & $43(37.7 \%)$ & 55 & $8(14.5 \%)$ & 0.002 & 71 & $26(36.6 \%)$ & 20 & $3(15 \%)$ & 0.068 \\
\hline Definite radiographic sacroiliitis, $\mathbf{N}(\%)$ & 111 & $32(28.8 \%)$ & 53 & $1(1.9 \%)$ & $<0.001$ & 71 & $16(22.5 \%)$ & 20 & $0(0 \%)$ & 0.020 \\
\hline $\begin{array}{l}\text { Active lesions typical of axSpA } \\
\text { (majority }(\geq 4 / 7) \text { of readers) } \mathrm{N}(\%)\end{array}$ & 109 & $39(35.8 \%)$ & 49 & $1(2.0 \%)$ & $<0.001$ & 69 & $23(33.3 \%)$ & 17 & $1(5.9 \%)$ & 0.034 \\
\hline
\end{tabular}




\begin{tabular}{|c|c|c|c|c|c|c|c|c|c|c|}
\hline $\begin{array}{l}\text { Active lesions typical of axSpA } \\
\qquad(\geq 2 / 7 \text { readers }) \mathrm{N}(\%)\end{array}$ & 109 & $62(56.9 \%)$ & 49 & $2(4.1 \%)$ & $<0.001$ & 69 & $27(39.1 \%)$ & 17 & $1(5.9 \%)$ & 0.009 \\
\hline $\begin{array}{l}\text { Structural lesions typical of axSpA } \\
\text { (majority }(\geq 4 / 7) \text { of readers) } \mathrm{N}(\%)\end{array}$ & 102 & $33(32.4 \%)$ & 44 & $3(6.8 \%)$ & 0.001 & 63 & $23(36.5 \%)$ & 16 & $0(0 \%)$ & 0.004 \\
\hline $\begin{array}{l}\text { Structural lesions typical of axSpA } \\
\qquad(\geq 2 / 7 \text { readers }) \mathrm{N}(\%)\end{array}$ & 102 & $48(47.1 \%)$ & 44 & $7(15.9 \%)$ & $<0.001$ & 63 & $28(44.4 \%)$ & 16 & $2(12.5 \%)$ & 0.018 \\
\hline
\end{tabular}

*169 cases with either active $(n=158)$ or structural $(n=146)$ MRI lesion detailed scoring data available plus local rheumatologist diagnostic assessment at baseline

**91 cases with either active $(n=86)$ or structural $(n=79)$ MRI lesion detailed scoring data available plus local rheumatologist diagnostic assessment at follow up 
Table 2. Performance of MRI lesion cut-offs for presence of definite active or structural lesion of $\operatorname{axSpA}$.

\begin{tabular}{|c|c|c|}
\hline $\begin{array}{l}\text { Cut-offs for number of SIJ Quadrants (any } \\
\text { location) }\end{array}$ & Sensitivity (95\% CI) & $\begin{array}{l}\text { Specificity }(95 \% \\
\text { CI) }\end{array}$ \\
\hline \multicolumn{3}{|c|}{ Majority $(\geq 4 / 7)$ reader agreement for definite active lesion* } \\
\hline BME Score $\geq 1$ & $100.0(86.8-100.0)$ & $71.6(63.2-79.1)$ \\
\hline BME Score $\geq 2$ & $100.0(86.8-100.0)$ & $85.8(78.7-91.2)$ \\
\hline BME Score $\geq 3$ & $100.0(86.8-100.0)$ & $91.8(85.8-95.8)$ \\
\hline BME Score $\geq 4$ & $100.0(86.8-100.0)$ & $96.3(91.5-98.8)$ \\
\hline \multicolumn{3}{|c|}{ Majority $(\geq 4 / 7)$ reader agreement for definite $A S A S$ positive $M R I^{*}$} \\
\hline BME Score $\geq 1$ & $100.0(86.8-100.0)$ & $71.6(63.2-79.1)$ \\
\hline BME Score $\geq 2$ & $100.0(86.8-100.0)$ & $85.8(78.7-91.2)$ \\
\hline BME Score $\geq \mathbf{3}$ & $100.0(86.8-100.0)$ & $91.8(85.8-95.8)$ \\
\hline BME Score $\geq 4$ & $100.0(86.8-100.0)$ & $96.3(91.5-98.8)$ \\
\hline \multicolumn{3}{|c|}{ Majority $(\geq 4 / 7)$ reader agreement for definite structural lesion ${ }^{\#}$} \\
\hline Erosion Score $\geq 1$ & $93.1(77.2-99.2)$ & $80.6(72.4-87.3)$ \\
\hline Erosion Score $\geq 2$ & $93.1(77.2-99.2)$ & $90.8(84.1-95.3)$ \\
\hline Erosion Score $\geq 3$ & 89.7 (72.6-97.8) & $95.8(90.5-98.6)$ \\
\hline Erosion Score $\geq 4$ & $86.2(68.3-96.1)$ & $95.8(90.5-98.6)$ \\
\hline Fat lesion Score $\geq 1$ & $82.8(64.2-94.2)$ & $81.5(73.4-88.0)$ \\
\hline Fat lesion Score $\geq 2$ & $69.0(49.2-84.7)$ & $86.6(79.1-92.1)$ \\
\hline Fat lesion Score $\geq \mathbf{3}$ & $62.1(42.3-79.3)$ & $91.6(85.1-95.9)$ \\
\hline Fat lesion Score $\geq 4$ & $62.1(42.3-79.3)$ & $94.1(88.3-97.6)$ \\
\hline
\end{tabular}




\begin{tabular}{|c|c|c|}
\hline Fat lesion Score $\geq 5$ & $62.1(42.3-79.3)$ & $97.5(92.8-99.5)$ \\
\hline Fat lesion $(>1 \mathrm{~cm}$ depth $) \geq 1$ & $58.6(38.9-76.5)$ & $95.0(89.3-98.1)$ \\
\hline Fat lesion $(>1 \mathrm{~cm}$ depth $) \geq 2$ & $55.2(35.7-73.6)$ & $95.8(90.5-98.6)$ \\
\hline Fat lesion $(>1 \mathrm{~cm}$ depth $) \geq 3$ & $51.7(32.5-70.6)$ & $97.5(92.8-99.5)$ \\
\hline Fat lesion $(>1 \mathrm{~cm}$ depth $) \geq 4$ & $41.4(23.5-61.1)$ & $98.3(94.1-99.8)$ \\
\hline Sclerosis $\geq 1$ & $75.9(56.5-89.7)$ & $76.5(67.8-83.8)$ \\
\hline Sclerosis $\geq 2$ & $65.5(45.7-82.1)$ & $85.7(78.1-91.5)$ \\
\hline Sclerosis $\geq 3$ & $44.8(26.4-64.3)$ & $89.9(83.0-94.7)$ \\
\hline Sclerosis $\geq 4$ & $41.4(23.5-61.1)$ & $90.8(84.1-95.3)$ \\
\hline Sclerosis $\geq 5$ & $27.6(12.7-47.2)$ & $93.3(87.2-97.1)$ \\
\hline Sclerosis $\geq 6$ & $24.1(10.3-43.5)$ & $94.1(88.3-97.6)$ \\
\hline Sclerosis $\geq 7$ & $20.7(8.0-39.7)$ & $95.8(90.5-98.6)$ \\
\hline Fat lesion score $\geq 1$ and Erosion score $\geq 1$ & $75.9(56.5-89.7)$ & $90.8(84.1-95.3)$ \\
\hline Fat lesion score $\geq 2$ and/or Erosion score $\geq 1$ & $96.6(82.2-99.9)$ & $74.0(65.1-81.6)$ \\
\hline Fat lesion score $\geq 2$ and/or Erosion score $\geq 2$ & $96.6(82.2-99.9)$ & $81.5(73.4-88.0)$ \\
\hline Fat lesion score $\geq \mathbf{3}$ and/or Erosion score $\geq 1$ & $96.6(82.2-99.9)$ & $77.3(68.7-84.5)$ \\
\hline Fat lesion score $\geq \mathbf{3}$ and/or Erosion score $\geq 2$ & $96.6(82.2-99.9)$ & $85.7(78.1-91.5)$ \\
\hline $\begin{aligned} \text { Fat lesion }(>1 \mathrm{~cm} \text { depth }) & \geq 1 \text { and Erosion score } \\
& \geq 1\end{aligned}$ & $55.2(35.7-73.6)$ & $99.2(95.4-100.0)$ \\
\hline $\begin{aligned} \text { Fat lesion ( }>1 \mathrm{~cm} \text { depth) } & \geq 1 \text { and/or Erosion } \\
\text { score } & \geq 1\end{aligned}$ & $96.6(82.2-99.9)$ & $76.5(67.8-83.8)$ \\
\hline $\begin{array}{c}\text { Fat lesion ( }>1 \mathrm{~cm} \text { depth }) \geq 1 \text { and/or Erosion } \\
\text { score } \geq 2\end{array}$ & $96.6(82.2-99.9)$ & $86.6(79.1-92.1)$ \\
\hline
\end{tabular}




\begin{tabular}{|c|c|c|}
\hline Fat lesion (>1cm depth) $\geq \mathbf{1}$ and/or Erosion & $93.1(77.2-99.2)$ & $90.8(84.1-95.3)$ \\
score $\geq \mathbf{3}$ & & \\
\hline
\end{tabular}

$* \mathrm{~N}=160 \quad \# \mathrm{~N}=148 \quad$ Cells in bold-face type indicate candidate MRI lesion cut-

offs achieving $\geq 95 \%$ specificity

BME, bone marrow edema; SIJ, sacroiliac joint; ASAS MRI-WG, Assessments in Spondyloarthritis International Society MRI Working Group 
Table 3. Performance of consecutive slices with MRI lesions for the presence of definite lesions of axSpA.

\begin{tabular}{|c|c|c|c|}
\hline & $\begin{array}{c}\text { Number of SIJ } \\
\text { slices }\end{array}$ & $\begin{array}{c}\text { Sensitivity (95\% } \\
\text { CI) }\end{array}$ & Specificity $(95 \%$ CI $)$ \\
\hline \multicolumn{4}{|c|}{ Majority $(\geq 4 / 7)$ reader agreement for definite active lesion* } \\
\hline BME & 2 & $100.0(86.8-100.0)$ & $88.1(81.3-93.0)$ \\
\hline BME & 3 & $100.0(86.8-100.0)$ & $94.8(89.5-97.9)$ \\
\hline BME & 4 & $96.2(80.4-99.9)$ & $98.5(94.7-99.8)$ \\
\hline \multicolumn{4}{|c|}{ Majority $(\geq 4 / 7)$ reader agreement for definite ASAS positive MRI* } \\
\hline BME & 2 & $100.0(86.8-100.0)$ & $88.1(81.3-93.0)$ \\
\hline BME & 3 & $100.0(86.8-100.0)$ & $94.8(89.5-97.9)$ \\
\hline BME & 4 & $96.2(80.4-99.9)$ & $98.5(94.7-99.8)$ \\
\hline \multicolumn{4}{|c|}{ Majority $(\geq 4 / 7)$ reader agreement for definite structural lesion ${ }^{\#}$} \\
\hline Erosion & 2 & $82.8(64.2-94.2)$ & $95.0(89.3-98.1)$ \\
\hline Erosion & 3 & $62.1(42.3-79.3)$ & $99.2(95.4-100.0)$ \\
\hline Erosion & 4 & $41.4(23.5-61.1)$ & $100.0(96.9-100.0)$ \\
\hline Fat lesion & 2 & $55.2(35.7-73.6)$ & $93.3(87.2-97.1)$ \\
\hline Fat lesion & 3 & $51.7(32.5-70.6)$ & $97.5(92.8-99.5)$ \\
\hline Fat lesion & 4 & $41.4(23.5-61.1)$ & $98.2(94.1-99.8)$ \\
\hline Fat lesion (>1cm depth) & 2 & $48.3(29.4-67.5)$ & $97.5(92.8-99.5)$ \\
\hline Fat lesion (>1cm depth) & 3 & $34.5(17.9-54.3)$ & $98.3(94.1-99.8)$ \\
\hline Fat lesion (>1cm depth) & 4 & $34.5(17.9-54.3)$ & $98.3(94.1-99.8)$ \\
\hline Sclerosis & 2 & $48.3(29.4-67.5)$ & $89.9(83.0-94.7)$ \\
\hline
\end{tabular}




\begin{tabular}{|c|c|c|c|}
\hline Sclerosis & 3 & $34.5(17.9-54.3)$ & $92.4(86.1-96.5)$ \\
\hline Sclerosis & 4 & $\mathbf{2 4 . 1}(\mathbf{1 0 . 3 - 4 3 . 5 )}$ & $\mathbf{9 5 . 8}(\mathbf{9 0 . 5}-98.6)$ \\
\hline
\end{tabular}

*N=160 $\quad \# \mathrm{~N}=148 \quad$ Cells in bold-face type indicate candidate MRI

lesion cut-offs achieving $\geq 95 \%$ specificity

BME, bone marrow edema; SIJ, sacroiliac joint; ASAS MRI-WG, Assessments in Spondyloarthritis International Society MRI Working Group 
Table 4. Predictive validity of baseline MRI lesions typical of axSpA according to rheumatologist's follow-up diagnosis.

\begin{tabular}{|c|c|c|c|c|}
\hline \multirow{2}{*}{ MRI scan at baseline } & \multicolumn{4}{|c|}{ Rheumatologist Diagnosis of axSpA at follow up } \\
\hline & Sensitivity & Specificity & PPV(\%) & NPV(\%) \\
\hline \multicolumn{5}{|c|}{ EXERCISE A* } \\
\hline $\begin{array}{l}\text { Active lesions typical of axSpA } \\
\qquad(\geq 2 \text { readers })\end{array}$ & $47.3(38.5-56.2)$ & $84.6(69.5-94.1)$ & 91.2 & 32.4 \\
\hline $\begin{array}{l}\text { Active lesions typical of axSpA } \\
\qquad(\geq 4 / 7 \text { readers })\end{array}$ & $44.3(35.6-53.2)$ & $94.9(82.7-99.4)$ & 96.7 & 33.6 \\
\hline $\begin{array}{c}\text { ASAS positive MRI } \\
(\geq 2 \text { readers })\end{array}$ & $45.0(36.3-54.0)$ & $87.2(72.6-95.7)$ & 92.2 & 32.1 \\
\hline $\begin{array}{l}\text { ASAS positive MRI } \\
\qquad \geq 4 / 7 \text { readers })\end{array}$ & $39.7(31.3-48.6)$ & $94.9(82.7-99.4)$ & 96.3 & 31.9 \\
\hline $\begin{array}{l}\text { Structural lesions typical of axSpA } \\
\qquad(\geq 2 \text { readers })\end{array}$ & $53.6(43.9-63.0)$ & $80.7(62.5-92.5)$ & 90.9 & 32.5 \\
\hline $\begin{array}{l}\text { Structural lesions typical of axSpA } \\
\qquad(\geq 4 / 7 \text { readers })\end{array}$ & $44.6(35.2-54.3)$ & $93.6(78.6-99.2)$ & 96.2 & 31.9 \\
\hline
\end{tabular}




\begin{tabular}{|c|c|c|c|c|}
\hline \multicolumn{5}{|c|}{ EXERCISE B** } \\
\hline $\begin{array}{l}\text { MRI indicative of } \operatorname{axSpA^{\# }} \\
\qquad(\geq 2 \text { readers })\end{array}$ & $56.3(45.3-66.9)$ & $85.7(63.7-97.0)$ & 94.2 & 32.1 \\
\hline $\begin{array}{c}\text { MRI indicative of axSpA } \\
(\geq 5 / 8 \text { readers })\end{array}$ & $50.6(39.6-61.5)$ & $100.0(83.9-100.0)$ & 100.0 & 32.8 \\
\hline $\begin{array}{l}\text { Active lesions typical of } \operatorname{axSpA} \\
\qquad(\geq 2 \text { readers })\end{array}$ & $47.3(38.5-56.2)$ & $84.6(69.5-94.1)$ & 91.2 & 32.4 \\
\hline $\begin{array}{l}\text { Active lesions typical of axSpA } \\
\qquad(\geq 5 / 8 \text { readers })\end{array}$ & $44.3(35.6-53.2)$ & $94.9(82.7-99.4)$ & 96.7 & 33.6 \\
\hline $\begin{array}{l}\text { ASAS positive MRI } \\
\qquad \geq 2 \text { readers })\end{array}$ & $53.6(43.9-63.0)$ & $80.7(62.5-92.5)$ & 90.9 & 32.5 \\
\hline $\begin{array}{l}\text { ASAS positive MRI } \\
\text { ( } \geq 5 / 8 \text { readers })\end{array}$ & $44.6(35.2-54.3)$ & $93.6(78.6-99.2)$ & 96.2 & 31.9 \\
\hline $\begin{array}{l}\text { Structural lesions typical of axSpA } \\
\qquad(\geq 2 \text { readers })\end{array}$ & $48.3(37.4-59.2)$ & 90.48 (69.6-98.9) & 95.5 & 29.7 \\
\hline Structural lesions typical of axSpA & $31.0(21.5-41.9)$ & $95.2(76.2-99.9)$ & 96.4 & 25.0 \\
\hline
\end{tabular}




\section{( $\geq 5 / 8$ readers)}

* $n=170$ with central reading of active MRI lesions at baseline and rheumatologist diagnosis at follow-up, $n=143$ with central reading of structural MRI lesions at baseline and rheumatologist diagnosis at follow-up

** $n=107$ with central reading of active and structural MRI lesions at baseline and rheumatologist diagnosis at follow up

\# This variable was only addressed in exercise B 
Table 5. Performance of MRI SIJ lesion cut-offs and slices for rheumatologist diagnosis of axSpA at follow-up.

\begin{tabular}{|c|c|c|c|c|}
\hline \multirow[b]{2}{*}{ Baseline MRI data* } & \multicolumn{2}{|c|}{ axSpA at Follow Up (yes/no) } & \multirow[b]{2}{*}{ PPV } & \multirow[b]{2}{*}{ NPV } \\
\hline & $\begin{array}{l}\text { Sensitivity } \\
(95 \% \mathrm{CI})\end{array}$ & $\begin{array}{l}\text { Specificity } \\
(95 \% \mathrm{CI})\end{array}$ & & \\
\hline BME Score $\geq 2$ SIJ quadrants & $47.8(35.6-60.2)$ & $82.4(56.6-96.2)$ & $91.7(79.3-96.9)$ & $28.0(22.1-34.8)$ \\
\hline BME Score $\geq 4$ SIJ quadrants & $31.9(21.2-44.2)$ & 94.1 (71.3-99.9) & 95.7 (76.1-99.3) & $25.4(21.8-29.4)$ \\
\hline BME $\geq 2$ consecutive slices & $43.5(31.6-56.0)$ & $82.4(56.6-96.2)$ & $90.9(77.6-96.7)$ & $26.4(21.0-32.7)$ \\
\hline BME $\geq 3$ consecutive slices & $30.4(19.9-42.7)$ & $100.0(80.5-100.0)$ & 100.0 & $26.2(23.3-29.3)$ \\
\hline Erosion Score $\geq 3$ SIJ quadrants & $38.1(26.1-51.2)$ & $93.8(69.8-99.8)$ & $96.0(77.8-99.4)$ & $27.8(23.4-32.6)$ \\
\hline Erosion Score $\geq 4$ SIJ quadrants & $36.5(24.7-49.6)$ & $93.8(69.8-99.8)$ & $95.8(77.0-99.4)$ & $27.3(23.0-32.0)$ \\
\hline Erosion $\geq 2$ consecutive slices & $38.1(26.1-51.2)$ & $93.8(69.8-99.8)$ & $96.0(77.8-99.4)$ & $27.8(23.4-32.6)$ \\
\hline Erosion $\geq 3$ consecutive slices & $36.5(24.7-49.6)$ & $100.0(79.4-100.0)$ & 100.0 & $28.6(24.9-32.5)$ \\
\hline Erosion $\geq 4$ consecutive slices & $30.2(19.2-43.0)$ & $100.0(79.4-100.0)$ & 100.0 & $26.7(23.6-30.0)$ \\
\hline
\end{tabular}




\begin{tabular}{|c|c|c|c|c|}
\hline Fat lesion $\geq 2$ SIJ quadrants & $42.9(30.5-56.0)$ & $93.8(69.8-99.8)$ & $96.4(79.8-99.5)$ & $29.4(24.5-34.8)$ \\
\hline Fat lesion $\geq 5$ SIJ quadrants & $31.8(20.6-44.7)$ & $93.8(69.8-99.8)$ & $95.2(74.3-99.3)$ & $25.9(22.0-30.1)$ \\
\hline Fat lesion $\geq 3$ consecutive slices & $30.2(19.2-43.0)$ & $93.8(69.8-99.8)$ & $95.0(73.3-99.2)$ & $25.4(21.7-29.5)$ \\
\hline Fat lesion $\geq 4$ consecutive slices & $20.6(11.5-32.7)$ & $100.0(79.4-100.0)$ & 100.0 & $24.2(22.0-26.6)$ \\
\hline Fat lesion $(>1 \mathrm{~cm}$ depth) $\geq 2$ SIJ quadrants & $25.4(15.3-37.9)$ & $100.0(79.4-100.0)$ & 100.0 & $25.4(22.8-28.2)$ \\
\hline Fat lesion $(>1 \mathrm{~cm}$ depth) $\geq 2$ consecutive slices & $23.8(14.0-36.2)$ & $100.0(79.4-100.0)$ & 100.0 & $25.0(22.5-27.7)$ \\
\hline Sclerosis $\geq 2$ SIJ quadrants & $33.3(22.0-46.3)$ & $87.5(61.7-98.4)$ & $91.3(73.3-97.6)$ & $25.0(20.5-30.1)$ \\
\hline Sclerosis $\geq 3$ SIJ quadrants & $30.2(19.2-43.0)$ & $87.5(61.7-98.4)$ & $90.5(71.1-97.3)$ & $24.1(19.9-28.9)$ \\
\hline Sclerosis $\geq 4$ SIJ quadrants & $28.6(17.9-41.3)$ & $87.5(61.7-98.4)$ & $90.0(69.9-97.2)$ & $23.7(19.6-28.4)$ \\
\hline Sclerosis $\geq 5$ SIJ quadrants & $22.2(12.7-34.5)$ & $87.5(61.7-98.4)$ & $87.5(63.9-96.5)$ & $22.2(18.5-26.4)$ \\
\hline Sclerosis $\geq 6$ SIJ quadrants & $19.1(10.5-30.9)$ & $87.5(61.7-98.4)$ & $85.7(59.8-96.0)$ & $21.5(18.0-25.5)$ \\
\hline
\end{tabular}




\begin{tabular}{|c|c|c|c|c|}
\hline Sclerosis $\geq 7$ SIJ quadrants & $15.9(7.9-27.3)$ & $87.5(61.7-98.4)$ & $83.3(54.8-95.4)$ & $20.9(17.6-24.7)$ \\
\hline Sclerosis $\geq 2$ consecutive slices & $33.3(22.0-46.3)$ & $87.5(61.7-98.4)$ & $91.3(73.3-97.6)$ & $25.0(20.5-30.1)$ \\
\hline Sclerosis $\geq 4$ consecutive slices & $15.9(7.9-27.3)$ & $87.5(61.7-98.4)$ & $83.3(54.8-95.4)$ & $20.9(17.6-24.7)$ \\
\hline
\end{tabular}

$* \geq 2$ reader data from detailed evaluation of baseline MRI DICOM cases $(91$ cases with either active $(\mathrm{n}=86)$ or structural $(\mathrm{n}=79)$ lesion baseline data and rheumatologist diagnosis at follow up)

Cells in bold-face type indicate candidate MRI lesion cut-offs achieving $\geq 95 \%$ specificity for a definite active or structural lesion as shown in Table 2

BME, bone marrow edema; SIJ, sacroiliac joint 
Figure 1. Examples of a positive SIJ MRI for active or structural lesions according to datadriven definitions. Row A illustrates an example of a positive MRI for an active lesion on short tau inversion recovery (STIR) MRI scans of 3 consecutive semicoronal slices through the sacroiliac joint. There is unequivocal BME in the right lower sacral SIJ quadrant in all 3 consecutive slices and in $\geq 4$ SIJ quadrants (asterisks in right lower iliac and left lower sacral SIJ quadrants)) thereby meeting the data-driven definition. Row B illustrates an example of a positive MRI for a structural lesion based on erosion on T1-weighted scans of 3 consecutive semicoronal slices through the sacroiliac joint. There is unequivocal erosion in the right lower iliac SIJ quadrant on 2 consecutive slices and in $\geq 3$ SIJ quadrants (asterisks in left lower iliac and right lower sacral SIJ quadrants) thereby meeting the data-driven definition. Row C illustrates an example of a positive MRI for a structural lesion based on fat lesions on T1-weighted scans of 3 consecutive semicoronal slices through the sacroiliac joint. There is a fat lesion in the left upper and lower sacral SIJ quadrants on all 3 consecutive slices and in $\geq 5$ SIJ quadrants (asterisks in right upper and lower sacral, right upper iliac, and left upper iliac SIJ quadrants) thereby meeting the data-driven definition. 

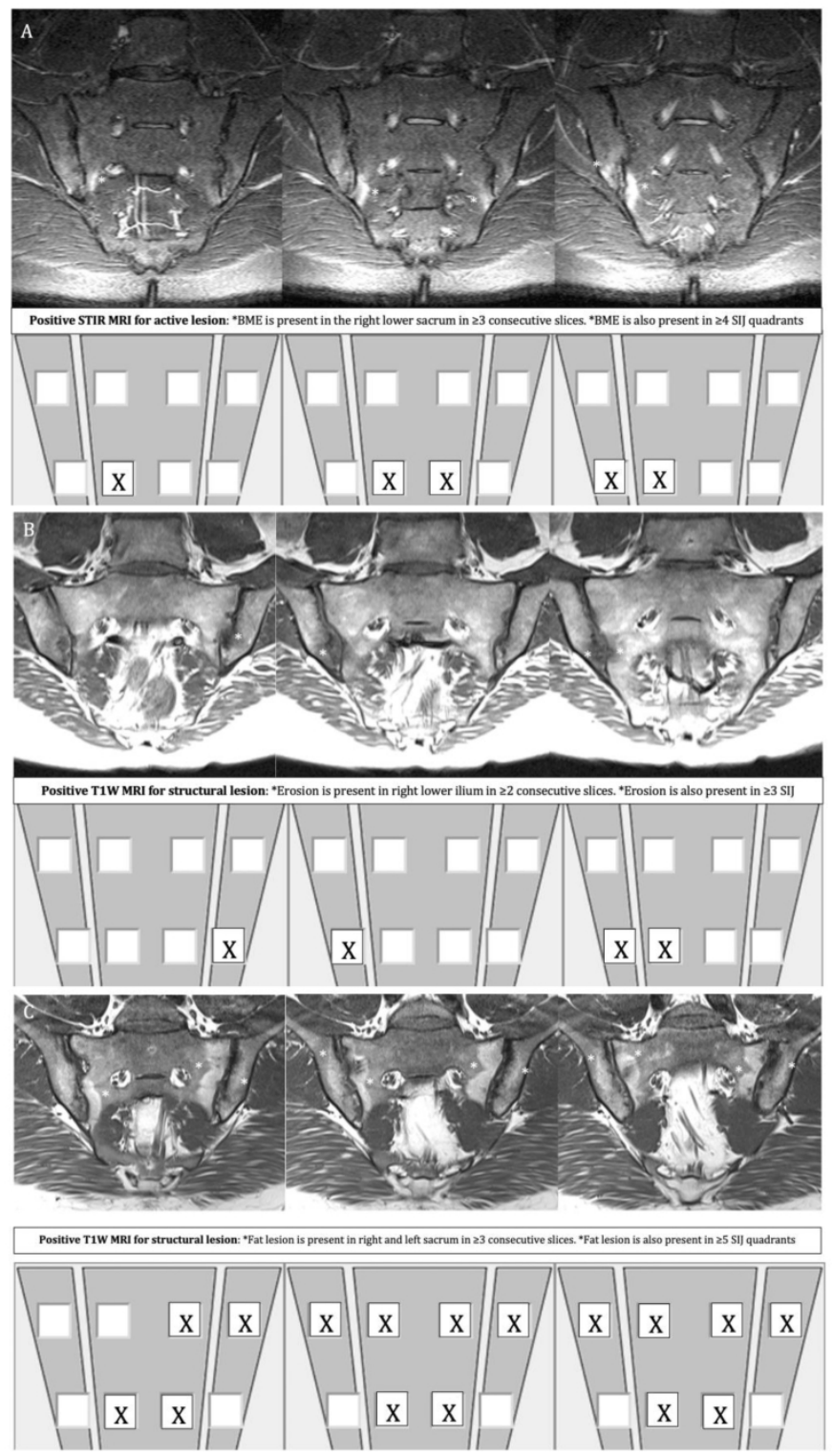

$137 \times 240 \mathrm{~mm}(300 \times 300$ DPI $)$ 